\title{
Lungenbeteiligung bei systemischer Sklerodermie
}

\author{
Lung Impairment in Systemic Sclerosis
}

Autoren

Institute
H. Knoop ${ }^{1}$, U. Arinir ${ }^{1}$, A. Kreuter ${ }^{2}$, J. W. Walther ${ }^{1}$, G. Schultze-Werninghaus ${ }^{1}$, G. Rohde ${ }^{1}$

Medizinische Klinik III - Pneumologie, Allergologie, Schlaf- und Beatmungsmedizin, Berufsgenossenschaftliche Universitätsklinik Bergmannsheil GmbH, Klinikum der Ruhr-Universität Bochum (Direktor: Prof. Dr. G. Schultze-Werninghaus)

2 Klinik für Dermatologie und Allergologie, St. Josef-Hospital, Klinikum der Ruhr-Universität Bochum (Direktor: Prof. Dr. P. Altmeyer) eingereicht 29.5.2009

akzeptiert 4.6 .2009

\section{Bibliografie}

DOI $10.1055 / \mathrm{s}-0029-1214908$

Online-Publikation: 25. 8. 2009

Pneumologie 2009; 63:

497-507 @ Georg Thieme Verlag KG Stuttgart · New York ISSN 0934-8387

\section{Korrespondenzadresse \\ Dr. Heiko Knoop}

Medizinische Klinik III Pneumologie, Allergologie, Schlaf- und Beatmungsmedizin Berufsgenossenschaftliche Universitätsklinik Bergmannsheil GmbH

Klinikum der Ruhr-Universität Bochum

Bürkle-de-la-Camp-Platz 1

44789 Bochum

Heiko.Knoop@

ruhr-uni-bochum.de

\section{Zusammenfassung \\ $\nabla$}

Unter dem Oberbegriff Sklerodermie werden heterogene Autoimmunerkrankungen zusammengefasst, die verdickte, sklerotische Hautläsionen gemein haben. Die Sklerodermie zählt zum Formenkreis der Kollagenosen. Die systemische Form der Sklerodermie wird als Progressive Systemische Sklerose (PSS) oder systemische Sklerodermie (SSc) bezeichnet. Die Lungenbeteiligung bei SSc in Form von interstitieller Lungenerkrankung (ILD) und pulmonal-arterieller Hypertonie (PAH) ist eine der häufigsten Manifestationen der Erkrankung. Das Ziel dieser Arbeit besteht darin, einen Überblick über die Formen des Lungenbefalls bei SSc mit besonderem Augenmerk auf die interstitiellen Lungenerkrankungen zu geben unter Berücksichtigung der bisher identifizierten pathogenetischen Mechanismen und der Therapieoptionen.

\section{Einleitung \\ $\nabla$}

Die systemische Sklerodermie ist eine autoaggressive entzündliche Bindegewebserkrankung mit Multiorganbefall [1]. Sie umfasst eine heterogene Gruppe von Erkrankungen, die sich durch verdickte, sklerotische Hautläsionen auszeichnen. Der Begriff Sklerodermie wurde 1847 von Gintrac eingeführt [2]. Bei ausschließlichem Hautbefall spricht man von zirkumskripter oder umschriebener Sklerodermie. Die systemischen Formen werden als Progressive Systemische Sklerose (PSS) oder systemische Sklerodermie (SSc) bezeichnet und nach LeRoy et al. in eine limitierte und eine diffuse kutane systemische Sklerodermie (lcSSc/dcSSc) unterteilt [3-5]. Zur Aufteilung in lcSSc und dcSSc werden u.a. Unterschiede in der Organbeteiligung, Differenzen bezüglich des Antikörperprofils und des Krankheitsverlaufs herangezogen. Wesentliche Charakteristika seien kurz aufgeführt:

\section{Abstract \\ $\nabla$}

Scleroderma is a generic term for autoimmunological diseases having thickened sclerotic skin lesions in common. Scleroderma belongs to a group of connective tissue diseases. The systemic form of scleroderma is called progressive systemic sclerosis (PSS) or systemic sclerosis (SSc). Lung impairments, namely interstitial lung disease (ILD) and pulmonary arterial hypertension (PAH), are one of the most common manifestations in SSc. This article summarises the forms of lung impairment in SSc with special emphasis on interstitial lung diseases and draws attention to the so far identified pathogenetic mechanisms and the presently accepted therapeutic options.
IcSSc: akrales Verteilungsmuster der Hautläsionen (beschränkt auf Hände und Unterarme), CREST-Syndrom (Calcinosis cutis, Raynaud-Syndrom (s. A Abb. 1), ösophageale Beteiligung, Sklerodaktylie, Teleangiektasien) ist möglich, selten Nierenbeteiligung, eine pulmonal-arterielle Hypertonie (mit oder ohne Lungengerüstprozess) kann ebenfalls auftreten - meistens spät im Krankheitsverlauf. Serologie: Antizentromeren-Antikörper (ACA) sind in ca. 70\% der Fälle positiv.

- dcSSc (s. $\odot$ Abb. 2): ein Raynaud-Syndrom ist zunächst nicht selten einziges Symptom, weitere Hautveränderungen (Akren/Körperstamm) folgen in der Regel innerhalb eines Jahres. Ein Organbefall tritt früh im Krankheitsverlauf auf, schließt vor allem Lunge, Magen-Darm-Trakt, Herz und Niere ein. Serologie: Antikörper gegen das extrahierbare immunoreaktive 70kDa-Fragment (Scl-70) von Topoisomerase (TOPO) I sind in $30 \%$ der 


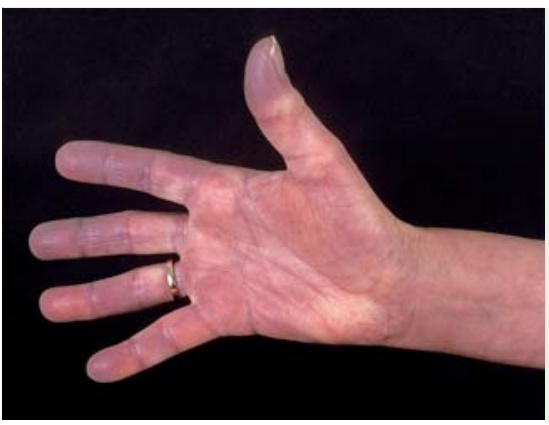

Abb. 1 Raynaud-Syndrom bei systemischer Sklerodermie.

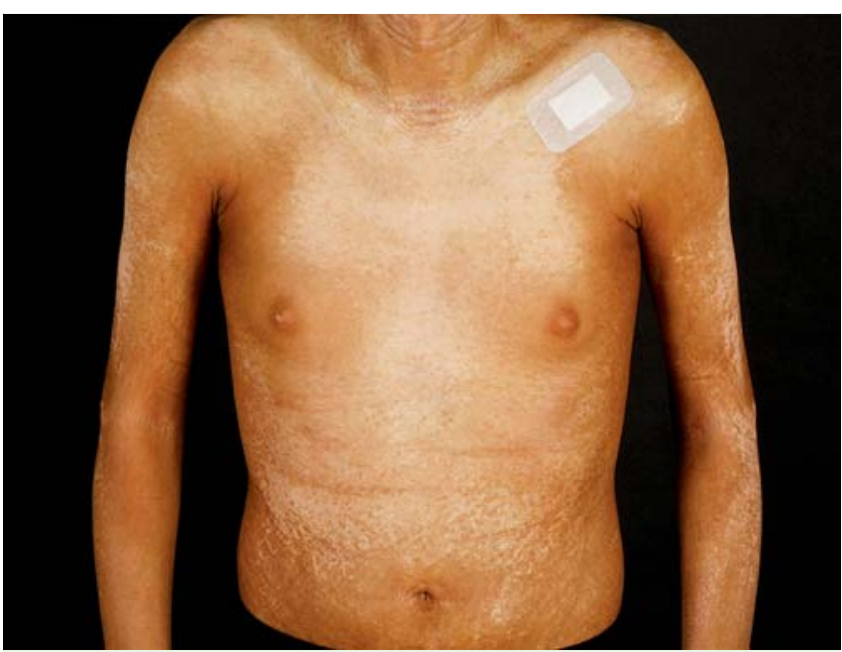

Abb. 2 Schwere, diffuse Hautsklerose bei Scl-70 positiver systemischer Sklerodermie.

Fälle positiv. Antikörper gegen RNA-Polymerase I, II und III in $15 \%[6]$.

Die Autoantikörper lassen sich in antinukleäre Antikörper (ANA) und als eine Unterform in Autoantikörper gegen extrahierbare nukleäre Antigene (ENA) unterteilen. Zu den ENA zählen neben anti-TOPO I-Antikörpern auch die ACA mit den Unterformen CENP-A und -B (Antikörper gegen Centromer-Protein A bzw. B). Im deutschsprachigen Raum ist die Klassifikation der Arbeitsgemeinschaft für dermatologische Forschung (ADF) etabliert [7]:

- Typ 1: Akraler Typ (häufigste Form mit betont vaskulärer Komponente)

- Typ 2: Proximal aszendierender Typ mit aszendierender Sklerosierung von Unter- und Oberarmen. Beteiligung von Verdauungstrakt, Lunge, Nieren und Leber (primär biliäre Zirrhose)

- Typ 3: Stammsklerodermie (Stammtyp) mit zentrifugaler Ausbreitung; Raynaud-Phänomen kann fehlen, Beteiligung von Gelenken und inneren Organen (Herz, Niere, Verdauungstrakt), febrile Temperatur

Typ 1 und 2 entsprechen der lcSSc, Typ 3 der dcSSc.

Zur Diagnosestellung einer Sklerodermie können nach wie vor die Kriterien des American College of Rheumatology (ACR) angewendet werden [8]. Die Diagnose gilt als gesichert, wenn der Patient das Haupt- oder zwei der drei Nebenkriterien erfüllt.

Hauptkriterium: Diffuse sklerotische Hautveränderungen (Verdickung, -härtung, -steifung der Haut) am Körperstamm (proximal)

\section{Nebenkriterien:}

- Sklerodaktylie (Finger und/oder Zehen)

- Rattenbissnekrosen/Substanzverlust an den Fingerballen

- beidseitige, basal lokalisierte Lungenfibrose
Für den Erkrankten steht der Hautbefall zumeist zuerst im Fokus der Aufmerksamkeit, da er sich in der Regel früh im Krankheitsverlauf bemerkbar macht [9]. In der dermatologischen Praxis wird zur Abschätzung des Schweregrades der Hautläsionen der modifizierte Rodnan Skin Score (mRSS) angewendet [10-13]. Beim mRSS werden 17 verschiedene Körperareale (Gesicht, Thorax, Abdomen, Oberarme, Unterarme, Hände, Finger, Oberschenkel, Unterschenkel, Füße) nach Palpation und Hautfältelung durch den Untersucher anhand einer Skala von 0 bis 3 beurteilt.

\section{Epidemiologie der systemischen Sklerodermie \\ $\nabla$}

Die Angaben zur Inzidenz schwanken abhängig vom Studiendesign, aber auch von genetischen und ethnischen Unterschieden. In den USA variiert die Inzidenz von ungefähr 4 bis 19 pro 1 Million Einwohner pro Jahr. Die Prävalenz liegt in den Vereinigten Staaten stabil bei ca. 240 Patienten pro 1 Million Einwohner in den letzten 20 Jahren [14,15]. Für Europa existieren Angaben aus den Niederlanden: hier beträgt die Prävalenz 8,9 pro 100000 Einwohner, die Inzidenz 0,77 pro 100000 [16]. Menschen mit dunkler Hautfarbe erkranken häufiger als Weiße [17]. Frauen sind deutlich häufiger betroffen (ca. 5:1 in Ergebnissen der EULAR (European League Against Rheumatism) und des German Network for Systemic Sclerosis) [18,19]. Das Durchschnittsalter bei Erkrankungsbeginn beträgt ca. 44 Jahre $[18,19]$. Der wichtigste, bisher identifizierte Risikofaktor, an SSc zu erkranken, ist eine positive Familienanamnese [20].

\section{Lungenbeteiligung bei systemischer Sklerodermie} $\nabla$

Es existieren mindestens vier unterschiedliche Formen der Lungenbeteiligung:

1. interstitielle Lungenerkrankung (Interstitial Lung Disease, ILD) (s. $\odot$ Abb. 3) inklusive Kapillaritis mit diffuser Hämorrhagie

2. pulmonal-arterielle Hypertonie (PAH)

3. Aspirationspneumonie und Bronchiektasenbildung infolge schwerer ösophagealer Dysmotilität mit daraus resultierendem gastroösophagealen Reflux und ggf. morphologischen

Veränderungen (Ösophagitis/Barrett-Ösophagus)

4. Bronchialkarzinom (v.a. bronchiolo-alveoläres Karzinom) [1] Eine pulmonale Hämorrhagie mit akutem Nierenversagen und diffuser alveolärer Hämorrhagie wurde selten beschrieben [21]. Die gehäuft bei systemischer Sklerodermie vorkommenden Bronchialkarzinome wurden als Narbenkarzinome bei fortschreitender Lungenfibrose interpretiert. Eine neuere Untersuchung zeigt aber, dass das Risiko für ein Bronchialkarzinom nicht durch die Lungenfibrose oder den Nachweis von anti-TOPO I-Antikörpern erhöht wird, sondern durch das inhalative Zigarettenrauchen bestimmt wird [22].

Lungenfibrose als eine Form einer ILD wird als ACR-Nebenkriterium genannt und belegt so die Bedeutsamkeit dieser Organmanifestation. Dies spiegelt sich auch in der Untersuchung der häufigsten Todesursachen bei SSc-Patienten wider: seit Einführung der ACE-Hemmer im Jahr 1980 lässt sich die SSc-bedingte Nierenbeteiligung wirksam behandeln [23]. Die pulmonalen Krankheitsfolgen ILD und PAH sind zur Haupttodesursache avanciert und nach dem gastrointestinalen Befall die zweithäufigste Organbeteiligung [19,24,25]. In der Vergangenheit konnten keine zuverlässigen Aussagen zur Häufigkeit von ILD und PAH bei SSc- 


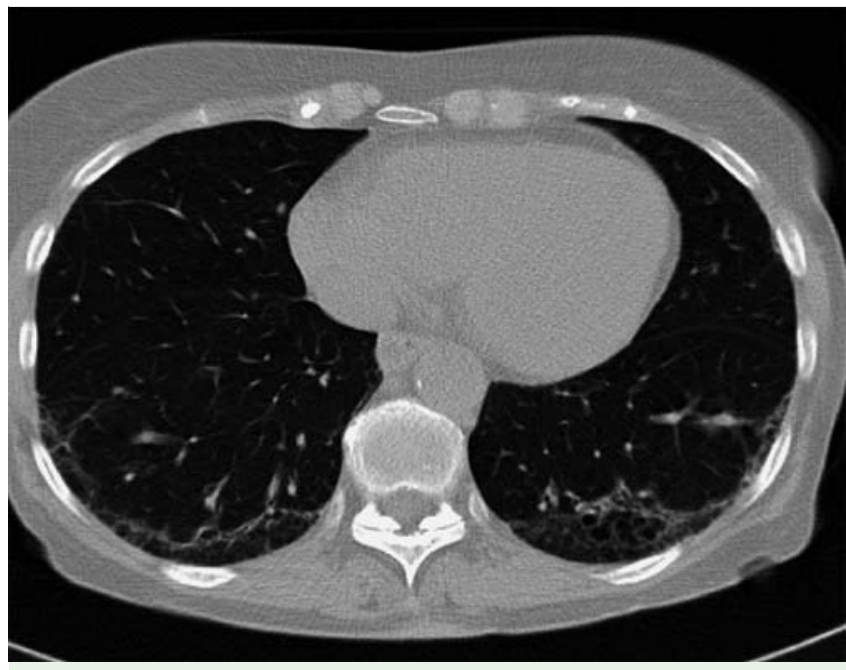

Abb. 3 Beidseitige subpleurale Fibrosierung bei systemischer Sklerodermie.

Patienten getroffen werden, da systematische Screeninguntersuchungen nicht durchgeführt wurden. Man weiß inzwischen, dass ein Großteil der Patienten eine solche Organmanifestation entwickelt. Die Angaben variieren zwischen 70 und 100\% [26-29]. Als Nachweisverfahren dienten Autopsie und CT-Thorax. Eine Unterscheidung der Lungenbeteiligung in PAH und ILD ist schwierig, da viele Patienten an beiden Krankheitsformen leiden. Eine signifikante Lungenbeteiligung kann bei $25 \%$ der Patienten bereits früh im Krankheitsverlauf beobachtet werden [30]. Dementsprechend werden heutzutage ein frühes Screening sowie engmaschige Kontrolluntersuchungen empfohlen [31].

\section{Sinnvolle Screeninguntersuchungen auf ILD/PAH bei SSc-Patienten}

Zur Beurteilung interstitieller Lungenveränderungen ist zunächst der bildmorphologische Befund von Interesse. Dank des technischen Fortschritts im Bereich der CT-Technik ist die Beurteilung im hochauflösenden CT (HR-CT) des Thorax in den letzten 20 Jahren zum Goldstandard geworden [32]. Zur Quantifizierung des Ausmaßes der beobachteten Veränderungen und zur Beantwortung der Frage nach dem Anteil von milchglasartigen Trübungen sowie nach Veränderungen im zeitlichen Verlauf werden in der internationalen Praxis semiquantitative Score-Systeme verwendet [33-35]. Milchglasartige Trübungen wurden früher in Zusammenhang mit florider Entzündungsaktivität (Alveolitis) gebracht. Sie sind jedoch nicht sehr spezifisch, sodass als weitere Diagnostik eine Bronchoskopie mit bronchoalveolärer Lavage (BAL) sinnvoll ist $[27,36]$. Mit den üblichen funktionellen Untersuchungen lässt sich objektivieren, welche Funktionsausfälle durch eine ILD oder PAH hervorgerufen werden [37]. Zu erwarten sind - auch bereits bei noch asymptomatischen Patienten mit SSc-ILD - restriktive Ventilationsstörungen [38], die sich entsprechend vor allem in einer Verminderung von TLC und FVC widerspiegeln - ebenso wie eine Verminderung der $\mathrm{T}_{\mathrm{LCO}}$ [37]. Auch infolge einer PAH kann es zu einer Verminderung der $\mathrm{T}_{\text {LCO }}$ kommen, sodass zur weiteren Differenzierung die Berechnung des Quotienten FVC/T $\mathrm{LCO}_{\mathrm{LO}}$ (jeweils in \% vom Soll) empfohlen wird [27]. Aufgrund der Volumenabhängigkeit der $\mathrm{T}_{\mathrm{LCO}}$ ist aus unserer Sicht der Krogh-Index ( $\mathrm{T}_{\mathrm{LCO}} /$ Alveolarvolumen in Prozent vom Soll) die geeignetere Beurteilungsgröße. Die genannten Parameter eignen sich ebenso wie die Blutgasanalyse in Ruhe und unter Belas- tungsbedingungen (6-Minuten-Gehtest (6-MWT) mit Längenangabe der Gehstrecke) für die Verlaufsbeurteilung [39]. Allerdings wurde in einer retrospektiven Untersuchung gezeigt, dass Schmerzen in den unteren Extremitäten bei Patienten mit SScILD und -PAH dazu führten, dass eine Belastungsgrenze hinsichtlich der Luftnotsymptomatik beim 6-MWT nicht erreicht werden konnte [40]. Versuche, die bildgebenden Befunde mit den Ergebnissen der Funktionsuntersuchungen zu korrelieren und daraus ein Staging-System zu entwickeln, sind ebenso beschrieben $[41,42]$. Zur Diagnosesicherung ist prinzipiell eine Biopsie zur genaueren histologischen Einordnung wünschenswert (Biopsie im Rahmen einer videoassistierten Thorakoskopie (VATS) oder transbronchialen Biopsie). Die VATS ist der offenen Lungenbiopsie im Rahmen einer Thorakotomie überlegen [43], da sie weniger invasiv ist und damit weniger Risiken birgt. Im Vergleich zur transbronchialen Biospie liefert sie qualitativ bessere Proben und gilt daher als Goldstandard zur Diagnosesicherung [27]. Bei koexistierender PAH werden Lungenbiopsien wegen des erhöhten Blutungsrisikos nicht empfohlen [44].

Zur Klärung der Frage einer PAH ist die jährliche transthorakale Echokardiografie als Screeningmethode angezeigt [45]. Als weitere Diagnostik sollte ggf. eine Einschwemmkatheteruntersuchung angeschlossen werden.

Des Weiteren sind wie bei jedem SSc-Patienten Laboruntersuchungen (inklusive Bestimmung von C-reaktivem Protein, Blutbild, Autoantikörpern) zu empfehlen.

\section{Interstitielle Lungenerkrankung (ILD) \\ $\nabla$}

- Abb. 4 gibt eine Übersicht über die systematische Einteilung der ILD. Entsprechend dem Consensus Statement der American Thoracic Society (ATS) und European Respiratory Society (ERS) werden idiopathische interstitielle Pneumonien (IIP) in die idiopathische Lungenfibrose (idiopathic pulmonary fibrosis, IPF) und non-IPF IIP unterschieden [46]. Die IPF stellt die häufigste Form der Lungenfibrosen dar [46]. Vor allem in Großbritannien findet darüber hinaus auch der Begriff kryptogen fibrosierende Alveolitis als Form einer IIP Anwendung [47]. Das histologische Korrelat zum klinischen Begriff IPF ist die Usual Interstitial Pneumonia. Die non-IPF IIP umfassen verschiedene klinische und histomorphologische Begriffe. Hierzu zählt auch die histologische Beschreibung Nonspecific Interstitial Pneumonia (NSIP). Dieser von Katzenstein und Fiorelli [48] eingeführte Begriff umfasst eine Gruppe von nicht-klassifizierbaren interstitiellen Pneumonien. In Abgrenzung zu den IIP werden die interstitiellen Pneumonien bei Systemerkrankungen, z. B. SSc gesehen. Der vorherrschende histologische Typ bei SSc-ILD ist die NSIP [49, 50]. Im Vergleich mit der idiopathischen NSIP zeigte sich bei SSc-NSIP ein deutlich stärkerer fibrotischer Prozess in Form einer höheren Dichte von Kollagenfasern im septalen Interstitium sowie einer höheren Dichte von elastischen Fasern entlang der septalen Interstitien und in den Gefäßwänden. Der Krogh-Index war bei den SSc-Patienten stärker eingeschränkt. Dennoch gab es hinsichtlich des Überlebens keine Unterschiede zwischen den beiden Gruppen [51].

\section{Pathogenese}

Die Pathogenese der SSc-ILD ist komplex. Sie umfasst immunologische Aktivierung, Entzündungsprozesse sowie Gefäßverletzung. Abb. 5 gibt einen Überblick über mögliche pathogenetische Zusammenhänge, wobei die zeitliche Abfolge der Ereignisse 
Interstitielle Lungenerkrankungen Interstitial Lung Diseases (ILDs)
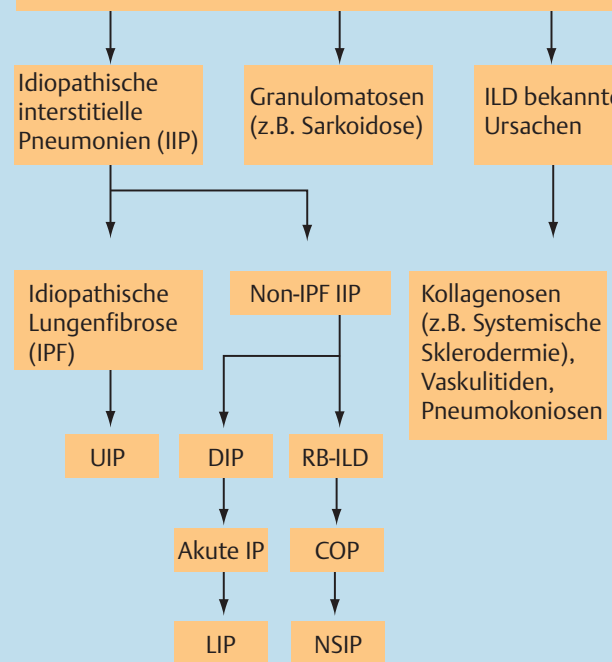

mehr gastroösophageale Refluxepisoden und mehr Refluat, das den proximalen Ösophagus erreicht [54]. Durch die Gewebsverletzung in der Lunge kommt es zur Apoptose und Aktivierung von Epithelzellen, die über eine Freisetzung von Zytokinen (Interleukinen) wiederum eine Entzündungsreaktion und Aktivierung von T- und B-Zellen sowie Makrophagen auslösen. Durch die Freisetzung von Zytokinen (Interleukinen, Interferonen) und Wachstumsfaktoren (Transforming Growth Factor (TGF)- $\beta$, Connective-Tissue Growth Factor (CTGF)) kommt es zur Aktivierung von Fibroblasten. Diese Aktivierung führt einerseits zur Akkumulation von Bestandteilen der extrazellulären Matrix (ECM) wie Proteoglykanen und Kollagen, andererseits unter Einfluss von TGF- $\beta$ zur Umwandlung der Fibroblasten zu Myofibroblasten. Diese ähneln Zellen der glatten Muskulatur und tragen über eine Verfestigung der extrazellulären Matrix zum fibrotischen Prozess bei. Myofibroblasten können auch durch EMT (Epithelial-Mesenchymal Transition) unter Einwirkung von TGF- $\beta$ und Endothelin-1 (ET-1) aus Epithelzellen entstehen [55].

Im Folgenden werden einzelne Studien zur Pathogenese der SSILD vorgestellt.

\section{Tiermodelle}

Statement 2002, in Anlehnung an [1]. Abkürzungen: UIP = Usual Interstitial Pneumonia, DIP = Desquamative Interstitial Pneumonia, RB-ILD = Respiratory Bronchiolitis associated Interstitial Pneumonia, COP = Cryptogenic Organizing Pneumonia, LIP = Lymphocytic Interstitial Pneumonia, NSIP = Nonspecific Interstitial Pneumonia.

unklar ist. Für die Pathogenese der SSc wird allgemein angenommen, dass eine Gefäßverletzung (durch Viren oder Autoantikörper) ein frühes Ereignis im Rahmen einer chronischen Entzündungsreaktion darstellt. Bei der SSc-ILD scheinen chronische Entzündungsprozesse ebenfalls eine besondere Rolle hinsichtlich des fibrotischen Umbauvorganges zu spielen. Hier wird der Entzündungsprozess möglicherweise durch eine unbekannte Gewebsverletzung - denkbar sind rezidivierende Aspirationen bei koexistierender Ösophagusbeteiligung - getriggert: neben dem Zusammenhang zwischen Ösophagitis/Barrett-Ösophagus und schwerer Ösophagusmotilitätsstörung konnte auf eine Korrelation zwischen schwerer Ösophagusmotilitätsstörung und SSc-ILD geschlossen werden [52,53]. Ferner haben Patienten mit SSc-ILD
Wesentliche Erkenntnisse über die Pathogenese von Lungenfibrose im Allgemeinen stammen aus Tiermodellen, bei denen Mäuse nach intratrachealer Bleomycingabe an Lungenfibrose erkrankten [56]. Eine britische Arbeitsgruppe entwickelte ein Modell mit transgenen Mäusen (T $\beta$ RII $\Delta \mathrm{k}$-fib) [57], die einen mutierten TGF- $\beta$-Rezeptor Typ II in Fibroblasten exprimierten. Diese Mutation bewirkt eine Liganden-abhängige Aktivierung von nachgeschalteten Signalwegen und erhöht die extrazelluläre Bioaktivität von TGF- $\beta$. TGF- $\beta$ ist ein Schlüsselmediator bei der Entstehung von Fibrose, und eine anhaltende Aktivierung von TGF- $\beta$ wird mit der Pathogenese der SSc in Verbindung gebracht [58]. Eine erhöhte Expression von TGF- $\beta 1$ und TGF- $\beta 2$ in Lungenbiopsien wurde ebenfalls beschrieben [59]. T $\beta R I I \Delta k$-fib-Mäuse und Bleomycin-behandelte Wildtyp-Mäuse zeigten in der Elektronenmikroskopie Schädigungen der Alveolarepithelzellen, erhöhte Kollagenanteile und Fibrosierung. Im Vergleich mit den gleichermaßen behandelten Wildtyp-Tieren zeigten die Bleomycinbehandelten transgenen Mäuse schwerere Schäden. Die morphologischen Veränderungen von mit Kochsalz behandelten trans-

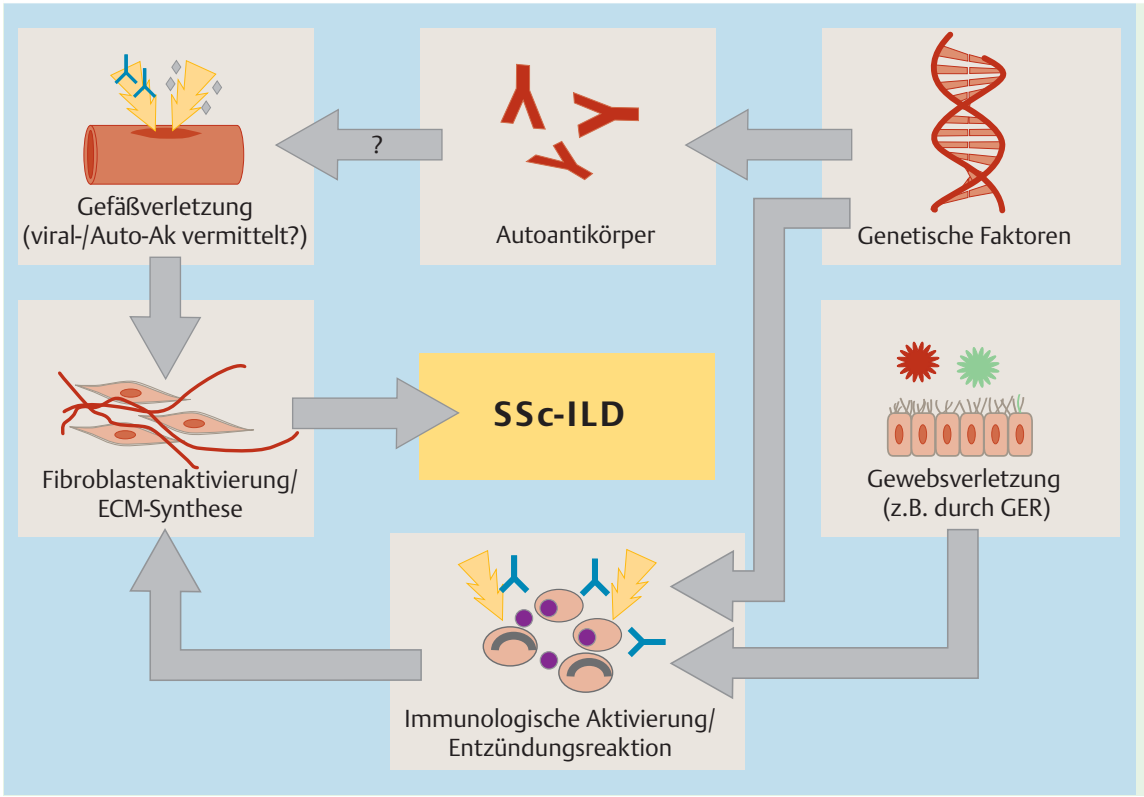

Abb. 5 Pathogenetische Mechanismen bei SSC-ILD. Abkürzungen: ECM = extrazelluläre Matrix, GER = gastroösophagealer Reflux. 
genen Mäusen glichen denen von Wildtyp-Mäusen, die mit Bleomycin behandelt wurden. Es wurde geschlussfolgert, dass die Störung des Fibroblasten-spezifischen TGF- $\beta$-Signalweges bereits bei kleineren Gewebsverletzungen eine signifikante Fibrosierung herbeiführt.

Inwieweit die Ergebnisse der Tiermodelle auf den Menschen übertragbar sind, bleibt wie bei jedem Tiermodell unklar. Ein erster Ansatzpunkt für In-vivo-Untersuchungen ergab sich mithilfe der Positronen Emissionstomografie (PET), bei dem für Patienten mit SSc-ILD tendenziell ein reduzierter Liganden-Uptake in Makrophagen bei erhöhter Dichte des Lungengewebes nachgewiesen wurde [60].

\section{Genetische Untersuchungen}

Es existieren umfassende genetische Untersuchungen im Zusammenhang mit SSc - die meisten überprüfen aber nicht den $\mathrm{Zu}$ sammenhang mit SSc-ILD, sondern mit dcSSc/lcSSc oder verschiedenen Autoantikörpern [61,62]. Im Zusammenhang mit SSc-ILD wurden nachfolgende Gene identifiziert:

CTGF kodiert für Connective-tissue growth factor (CTGF), einen Wachstumsfaktor, dem eine Bedeutung bei der Fibroblasten-Proliferation, der Bildung von extrazellulärer Matrix sowie von Adhäsions- und Granulationsgewebe zukommt. Ein single-nucleotide Polymorphismus (SNP) in der Promotorregion von CTGF (G945C) zeigte eine Assoziation mit SSc: das Vorhandensein eines C-Allels ist bedeutsam für die Unterdrückung der Transkription von CTGF. Homozygote G-Allel-Träger wiesen darüber hinaus vermehrt spezifische Antikörper (anti-TOPO I-Antikörper und ACA) sowie ein höheres Risiko einer ILD auf [63]. Eine weitere Assoziation konnte hergestellt werden zwischen Polymorphismen in NRAMP1 (INT4 $(469+14 \mathrm{G} / \mathrm{C})$ und $\left.5^{\circ}(\mathrm{GT})_{\mathrm{n}}\right)$ und SSc-ILD. NRAMP1 kodiert für das Natural Resistance Associated Macrophage Protein 1 (NRAMP1), das über verschiedene Mechanismen (u.a. Hochregulieren von Chemo-/Zytokin-Genen, Tumor Nekrose Faktor $\alpha$, Interleukin 1-b) zur Aktivierung von Makrophagen beiträgt [64]. Protektiv ist das Vorliegen eines SNP im Surfactant Protein $B$-Gen (SP-B): In einem japanischen Untersuchungskollektiv kam der T/T-Genotyp in SP-B (1580 C/T (Thr131Ile)) bei SSc-Patienten mit ILD signifikant seltener als bei denen ohne ILD vor [65]. Dieudé et al. [66] zeigten einen Zusammenhang zwischen einem SNP im IRF5-Gen und systemischer Sklerodermie. Das IRF5-Gen kodiert für einen Interferon (IFN)-Regulationsfaktor, der eine wichtige Rolle bei der virus-induzierten Immunaktivierung und der Regulation von IFN Typ 1 spielt. IFN Typ 1 bezeichnet eine Familie von Interferonen (Interferon $\alpha, \beta, \delta, 0, \tau$ ), die einen wichtigen Mediator des angeborenen Immunsystems darstellen. So stimuliert IFN Typ 1 die Reifung von Monozyten zu dendritischen Zellen ebenso wie die von Plasmazellen, den Switch von Immunglobulinen innerhalb der verschiedenen Immunglobulinklassen, die Aktivität von zytotoxischen T- und natürlichen Killerzellen sowie die Sekretion von Chemokinen. Für das IRF5-Gen wurde für das T-Allel von rs2004640 zuvor bereits ein Zusammenhang mit anderen Autoimmunerkrankungen gezeigt. Die Untersuchung von Dieudé et al. konnte darüber hinaus eine signifikante Assoziation zwischen dem T-Allel und SSc-ILD nachweisen. Ein signifikanter Zusammenhang konnte darüber hinaus hergestellt werden zwischen zwei Polymorphismen (+ 785 CC und + 1208 TT) in CXCR-2 (chemokine ( $c-x-c)$ motif receptor-Gen entspricht Interleukin-8-Rezeptor-Gen) und dem Auftreten von SSc sowie SSc-ILD. CXCR-2 kodiert für einen Interleukin-8 Rezeptor, über den Interleukin-8 seine Wirkung als potentes Chemokin auf Neutrophile ausübt [67]. Ferner wurde eine As- soziation zwischen IL10 (Interleukin 10-Gen) Polymorphismen und SSc-ILD hergestellt (1082 G/A Allele oder Haplotypen, die diese Allele enthalten) [68]. Eine brasilianische Arbeitsgruppe untersuchte ferner Varianten in Gensegmenten von TCRBV3S1 ( $T$-cell receptor beta variable 3-1-Gen), das für eine variable Region der $\beta$-Kette des T-Zellrezeptors kodiert. Allel 1 von TCRBV3S1 steht im Bezug zu einer geringen Häufigkeit von Vbeta3.1-positiven T-Zellen. Träger dieses Allels hatten eine höhere Prävalenz für SSc-ILD, sodass die Autoren von einem protektiven Effekt der genannten T-Zellen ausgehen [69]. Zusammenfassend konnte bisher vor allem für Mediatoren bzw. Rezeptoren, die in immunologischen und Entzündungsprozessen eine Rolle spielen, eine genetische Prädisposition für eine SSc-ILD gezeigt werden. Diese Ergebnisse belegen einerseits die Bedeutsamkeit jedes einzelnen dieser Mediatoren/Rezeptoren für die Pathogenese der SSc-ILD. Andererseits wird deutlich, dass die Erkrankung multifaktoriell bedingt ist und weitere Studien notwendig sind, um das Zusammenspiel der einzelnen Faktoren besser zu verstehen.

\section{Untersuchungen der BAL}

Neben diesen genetischen Studien finden sich in der Literatur zahlreiche Publikationen zur BAL-Flüssigkeit (BALF) bei SSc-ILD: Es wurde eine Korrelation zwischen der Zellzusammensetzung in der BALF und der Mortalität, Lungenfunktionsmessungen im Längsschnitt und der Dauer des progressionsfreien Intervalls untersucht [70]. Es zeigte sich zwar, dass eine hohe Entzündungsaktivität in Form einer Neutrophilie in der BALF mit einer frühen Mortalität verknüpft ist. Weitere Zusammenhänge zur Dauer des progressionsfreien Intervalls oder zur Geschwindigkeit der Verschlechterung der Lungenfunktion ließen sich jedoch nicht ableiten. Die Autoren folgerten, dass der Wert der BAL für die Definition von Krankheitsaktivität bei SSc-Patienten mit ILD fraglich ist. In der BALF von 18 SSc-Patienten [71] konnten neben einer erhöhten Gesamtzellzahl und einem erhöhten Anteil von Neutrophilen im Vergleich zu den 10 Kontrollen eine höhere Konzentration des löslichen Interleukin-2-Rezeptors (sIL-2R) nachgewiesen werden. Interessanterweise konnten keine Unterschiede zwischen Patienten mit und ohne SSc-ILD gezeigt werden. Dies wurde als Ausdruck einer ständigen subklinischen pulmonalen Entzündungsreaktion gewertet. Interleukin-2 wurde nicht nachgewiesen. Im Rahmen einer weiteren Studie zur BALF-Zusammensetzung wurden die Konzentrationen von Matrix Metalloprotease-9 (MMP-9), der Vorstufe pro-MMP-9 und dem natürlichen Inhibitor (Tissue Inhibitor of Matrix Metalloproteinase-1, TIMP1) bestimmt. MMP dienen dem effizienten Abbau von Kollagen und aktivieren Tumor Nekrose Faktor (TNF) $\alpha$. Die Konzentrationen von MMP-9 und seiner Vorstufe waren signifikant erhöht bei Patienten mit SSc-ILD, verglichen mit SSc-Patienten ohne ILD und gesunden Kontrollen. Ferner korrelierten die Konzentrationen von aktivem MMP-9, seiner Vorstufe und die Gesamtkonzentration beider MMP-9-Formen invers mit der totalen Lungenkapazität - ebenso wie die Quotienten aus pro-MMP/TIMP-1 und MMP9/TIMP-1 [72]. Eine schwedische Arbeitsgruppe isolierte Fibroblasten aus der BALF von Patienten mit SSc-ILD (Alveolitis) und Kontrollen und verglich diese hinsichtlich ihrer Proliferation, Migrationsfähigkeit, stress fibers und Proteoglykan-Synthese mit Fibroblasten, die im Rahmen von Lungenbiopsien bei denselben Untersuchungsgruppen gewonnen wurden. Stress fibers sind lange Aktinbündel, die von der Zellmitte in Bewegungsrichtung ausgehen und für Adhäsion und Zusammenhalt der Fibroblasten wichtig sind. Bei vier von 10 untersuchten Patienten gelang die Isolierung von Fibroblasten und damit insbesondere bei den Pa- 
tienten, die verglichen mit den Kontrollen einen bemerkenswert hohen Eosinophilenanteil in der BALF zeigten. Die Höhe des prozentualen Anteils an Eosinophilen korrelierte mit der Konzentration an Granulozyten-Makrophagen Kolonie-stimulierendem Faktor (GM-CSF). Die BALF-Fibroblasten waren länger und mobiler als die Fibroblasten in den Lungenbiopsien und zeigten eine höhere Proteoglykansynthese. Eine Interaktion zwischen Eosinophilen und Fibroblasten könnte eine Rolle bei der Entstehung einer SSc-ILD spielen [73].

Die Zellzusammensetzung in der BALF wurde ferner hinsichtlich ihres prädiktiven Wertes für den Krankheitsprogress und das Therapieansprechen auf Cyclophosphamid untersucht. Zwar zeigte die BALF in 71,6\% der untersuchten Patienten mit SSc-ILD eine pathologische Zellzusammensetzung und definierte so eine Subgruppe mit einem höheren Anteil an männlichen Patienten, schlechterer Lungenfunktion (TLC, FVC, $\mathrm{T}_{\mathrm{LCO}}$ ), Milchglastrübungen sowie mehr fibrotischen Veränderungen im Lungenmittellappen im CT. Dennoch ist die pathologische Zellzusammensetzung in der BALF kein unabhängiger Prädiktor für den Krankheitsverlauf oder das Ansprechen auf Cyclophosphamid nach einjähriger Therapie [74].

\section{Autoantikörper und Biomarker}

Es gibt zahlreiche Untersuchungen zu den Autoantikörpern bei SSc [75] - auch bezüglich ihrer Verbindung zu bestimmten Formen der Lungenbeteiligung [25]. Das Vorhandensein von antiTOPO I-Antikörpern scheint mit einem erhöhten Risiko für ILD verbunden zu sein [76] und eine Bedeutung für die Mortalität der SSc zu haben [77]. Eine direkte Beteiligung der Autoantikörper an der SSc-Pathogenese ist nicht bewiesen [78]. Die Sensitivität und Spezifität der Autoantikörper und die fehlende Möglichkeit, durch Bestimmung des Titers valide Aussagen über die Krankheitsaktivität treffen zu können, hat die Suche nach zuverlässigen Biomarkern gestärkt. Sie wird vor allem von dem Wunsch getrieben, ein nicht-invasives Untersuchungsverfahren zu etablieren, mit dem sich Aussagen zur Krankheitsaktivität machen lassen. Untersucht wurden Serumkonzentrationen von Surfactant-Proteinen [79] und des Mucin-assoziierten Antigens KL-6 (Krebs von den Lungen-6) [80,81]. In einer neueren Untersuchung wurden erhöhte Serumkonzentrationen von polymorphnukleärer neutrophiler Leukozyten Elastase (PMN) bei SSc-Patienten gemessen. Es zeigte sich darüber hinaus ein Trend zu höheren Werten bei Patienten mit SSc-ILD[82]. Unterschiede in den Serumkonzentrationen von Interleukin-8, löslichem (s)ICAM-1 (intracellular adhesion molecule) und sVCAM-1 (vascular cell adhesion molecule) ließen sich im Vergleich von SSc-Patienten mit und ohne ILD und Kontrollen nicht nachweisen [83].

Keiner der Marker konnte studienübergreifend eine hohe Sensitivität und Spezifität nachweisen. Die Aussagekraft der Studien war durch geringe Patientenzahlen limitiert. Als weiteres nichtinvasives Untersuchungsinstrument wurde die Bestimmung von Stickstoffmonoxid (NO) in der Ausatemluft überprüft. SSc-Patienten wurden mittels transthorakaler Echokardiografie, HR-CT und Lungenfunktionsprüfung untersucht und in zwei Gruppen (SScILD+ und -) aufgeteilt. Es konnte gezeigt werden, dass die aus der Ausatemluft berechnete alveoläre Konzentration von NO ( $\mathrm{CA}$, $\mathrm{NO})$ bei SSc-Patienten höher war als bei Kontrollen, und - im Gegensatz zu einer anderen Untersuchung [84] - in der SSc-ILD+-Gruppe signifikant höher war als in der SSc-ILD-Gruppe. Darüber hinaus ergab sich eine inverse Korrelation zwischen der CA, , $_{\mathrm{NO}}$ zur TLC und $\mathrm{T}_{\mathrm{LCO}}$ sowie eine direkte Korrelation zum CT-Fibrosescore. Es wurde gefolgert, dass die erhöhte $\mathrm{CA}_{\text {,NO }}$ entweder den Schwere- grad der Lungenerkrankung widerspiegelt oder sogar zur Verschlechterung beiträgt [85].

\section{Therapie}

Es gibt bislang keine sicher wirksame Therapie. Die Behandlung der SSc-ILD besteht weiterhin in erster Linie aus den immunmodulatorischen Substanzen Cyclophosphomid (CYC), Azathioprin (AZA) und Glukokortikosteroiden. Für keines der genannten Präparate existiert die nötige Evidenz, um eine Empfehlung zur Standardtherapie auszusprechen.

In der Scleroderma Lung Study (SLS) wurde CYC per os (p.o.) bei Patienten mit SSc-ILD gegen Placebo untersucht [86]. Die 145 eingeschlossenen Patienten erhielten CYC bzw. Placebo für mindestens ein halbes Jahr. Primärer Endpunkt der Studie war die FVC nach 12 Monaten. Es zeigte sich ein signifikanter, aber moderater Therapieerfolg in Form einer Verbesserung der FVC um 2,53 Prozent im Vergleich zwischen CYC- und Placebogruppe. Die besten Effekte zeigten sich bei Patienten mit im HR-CT gesicherter ausgedehnter Lungenfibrose. 12 Monate nach Beendigung der oralen CYC-Therapie konnten die Behandlungseffekte nicht mehr nachgewiesen werden [87], sodass eine Dauertherapie sinnvoll scheint. Ferner wurde die Wirksamkeit von CYC in der intravenösen (i.v.) Darreichungsform anhand von Lungenfunktionsparametern (FVC/\%Soll, $\mathrm{T}_{\mathrm{LCO}} / \%$ Soll) überprüft: von 59 Patienten mit SSc-ILD erhielten 29 intravenös CYC, 18 zusätzlich eine hochdosierte und 41 ebenfalls zusätzlich eine niedrigdosierte Prednisolon-Therapie [88]. Nach Gabe von hohen CYC-Dosen (mehr als 12 Gramm) zeigte sich eine sechsfach höhere Wahrscheinlichkeit zur Verbesserung der FVC (= Anstieg um mehr als 10 Prozent vom Soll) als zur Verschlechterung oder Stagnation. Für Steroide war kein positiver Effekt nachweisbar. Ferner zeigte eine Behandlungsdauer von mehr als einem Jahr eine höhere Wahrscheinlichkeit zur Verbesserung der Lungenfunktion.

Eine weitere Studie untersuchte die Wirksamkeit von 6 i.v.-Gaben von CYC in der Kombination mit einer niedrig-dosierten Prednisolontherapie p.o. gefolgt von AZA p.o. oder Placebo [89] bei SSc-Patienten mit Lungenfibrose. Primäre Endpunkte waren Veränderungen der FVC/\% vom Soll und der $\mathrm{T}_{\mathrm{LCO}}$, sekundäre Endpunkte morphologische Veränderungen im HR-CT sowie Dyspnoe-Scores. Es ergab sich keine statistische Signifikanz hinsichtlich beider Endpunkte. Einzig für die FVC zeigte sich ein Trend zu Gunsten der AZA-Gruppe. Eine andere Untersuchung überprüfte die Wirksamkeit einer sechsmonatigen i.v. CYC-Therapie, gefolgt von einer achtzehnmonatigen AZA-Behandlung p.o. bei SSc-ILD [90]. Hier zeigte sich nach einem halben Jahr bei $70 \%$ der Patienten eine Stabilisierung oder Verbesserung der FVC, nach 2 Jahren bei 51,8\% der Patienten. AZA als Monotherapie oder - bei klinischer Verschlechterung - in Kombination mit Prednison wurde ebenfalls bei SSc-Patienten mit ILD untersucht [91]. Ein Therapieansprechen wurde anhand der FVC eingeschätzt. Eine Verbesserung wurde als Anstieg der FVC von mehr als 10\%/Soll im Vergleich zum Vorwert definiert. Ein stabiler Zustand als Veränderung von weniger als $10 \% /$ Soll im Vergleich zur jeweiligen Voruntersuchung. Von 11 Patienten zeigten fünf eine Verbesserung und 3 eine Stabilisierung, sodass AZA eine Wirksamkeit zugestanden wurde.

Eine aktuelle Untersuchung [92] überprüfte die Wirksamkeit einer Kombinationstherapie aus CYC und dem TyrosinkinaseInhibitor Imatinib bei fünf Patienten mit SSc-ILD. Imatinib blockiert PDGFR (platelet derived growth factor receptor) und wird u. a. in der Behandlung der chronisch-myeloischen Leukämie eingesetzt. Darüber hinaus wurde der Einsatz bei rheumatoider $\mathrm{Ar}$ - 


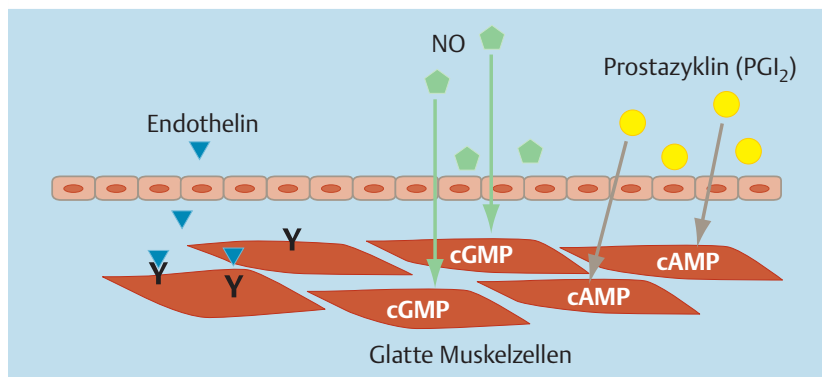

Abb. 6 Pathogenese der PAH. $\mathrm{NO}=$ Stickstoffmonoxid, $\mathrm{Y}=$ Endothelin $\mathrm{A}-$ Rezeptor, $\mathrm{cAMP}=$ zyklisches Adenosinmono-phosphat, $c \mathrm{GMP}=$ zyklisches Guanosinmonophosphat.

thritis beschrieben [93]. Bei SSc-Patienten wurden stimulierende Antikörper gegen PDGFR nachgewiesen, die zu einer vermehrten Genexpression von Kollagen Typ I und zur Konversion von Myofibroblasten zu „normalen“ Fibroblasten führten [94]. Von den fünf Patienten zeigten vier eine schwer- und einer eine mittelgradige restriktive Ventilationsstörung. Eine klinische Verbesserung ergab sich lediglich für den Patienten mit der mittelgradigen restrikten Ventilationsstörung. Aktuell wird durch die University of California bei Patienten mit SSc-ILD eine Studie zur Wirksamkeit und Verträglichkeit von Imatinib durchgeführt. Geplant ist der Einschluss von 20 Patienten (http://www.clinicaltrials.gov).

Der Einsatz von Glukokortikosteroiden erfolgt vor allem bei Hinweisen auf Alveolitis in der BAL oder im HR-CT, wobei bereits darauf hingewiesen wurde, dass die Sensitivität des CTs für die Diagnose einer Alveolitis eingeschränkt ist und die Diagnose einer Alveolitis anhand der BALF nicht zwingend eine Aussage zur Krankheitsaktivität zulässt [70]. Darüber hinaus ist die Wirksamkeit von Glukokortikosteroiden nicht eindeutig belegt [88]. Eine Langzeittherapie mit dieser Substanzklasse kann den Verlauf eher ungünstig beeinflussen, und Fälle von akutem Nierenversagen bei SSc-Patienten sind unter dieser Medikation beschrieben [95]. Es gibt keinen Beleg für die Wirksamkeit des zur Behandlung der Hautläsionen oft verwendeten Methotrexat (MTX) auf die ILD-SSc [96]. Da MTX darüber hinaus selbst eine Pneumonitis hervorrufen kann [97], wird es nicht für die Behandlung der ILDSSc empfohlen.

Die Anwendung anderer Präparate ist Gegenstand von Untersuchungen: beispielsweise wird Mycophenolat-Mofetil (MMF) gegenwärtig im Rahmen einer randomisierten doppelblinden kontrollierten Studie von der SLS-Forschergruppe hinsichtlich Wirksamkeit und Sicherheit in der Anwendung gegen CYC p.o. verglichen [98]. MMF ist ein Inosinmonophosphat-Dehydrogenase-Inhibitor, der die De-novo-Synthese von Guanosinnukleotiden, die Proliferation von T- und B-Lymphozyten und auch die Antikörperproduktion hemmt.

Bei SSc-Patienten mit schlechter Prognose wurde ferner im Rahmen einer einarmigen Phase 2-Studie die Wirksamkeit einer hochdosierten immunsuppressiven Therapie (HDIT) und autologen CD34-selektionierten hematopoetischen Zelltransplantation überprüft [99]. Die HDIT beinhaltete eine Bestrahlungstherapie der Lunge sowie medikamentöse Therapie mit CYC und equinem (vom Pferd) Antithymozyten-Globulin. 17 von 27 Patienten, die mindestens ein Jahr überlebten, zeigten im Verlauf anhaltende Therapieeffekte. Diese Effekte spiegelten sich vor allem in einer auch histologisch gesicherten Verbesserung des Hautbefundes sowie des Wohlbefindes (Fragebogenanalyse) wider. Hinsichtlich der Lungenbeteiligung konnte ein stabiler Zustand erzielt wer- den. Eine japanische Arbeitsgruppe veröffentlichte einen CaseReport über einen Patienten mit SSc-ILD, bei dem ebenfalls nach non-myeloablativer allogener hematopoetischer Stammzelltransplantation eine Stabilisierung der Lungenfunktion beobachtet werden konnte [100]. Aktuell wird eine kontrollierte prospektive Multicenter-Studie zum Vergleich der autologen Stammzelltransplantation mit der i.v. CYC-Stoßtherapie bei Patienten mit schweren Formen der systemischen Sklerodermie durchgeführt (Autologous Stem Cell Transplantation International Scleroderma Trial, ASTIS, http://www.astistrial.com/ASTIShome.HTM).

In Abwesenheit eindeutig wirksamer medikamentöser Therapieansätze ist die Lungentransplantation (LTx) als letzte Therapieoption zu nennen $[101,102]$.

\section{Pulmonal-arterielle Hypertonie (PAH) \\ $\nabla$}

Eine manifeste PAH liegt vor bei einer Erhöhung des pulmonalarteriellen Mitteldrucks ( $\mathrm{PAP}_{\mathrm{m}}$ ) in Ruhe $\geq 25 \mathrm{mmHg}$ mit pulmonal-kapillärem Wedge-Druck (PCWP) $\leq 15 \mathrm{~mm} \mathrm{Hg}$ und pulmonal-vaskulärem Widerstand $(\mathrm{PVR}) \geq 3$ Wood-Einheiten (entspricht $240 \mathrm{dyn} / \mathrm{s} / \mathrm{cm}^{5}$ ) [103]. Nach der Venedig-Klassifikation aus dem Jahr 2003 bildet die PAH die Gruppe 1, die PAH, assoziiert mit Bindegewebserkrankungen (APAH-CTD) ohne ILD, wird der Gruppe 1.3.1 zugerechnet [104]. Eine Erneuerung dieser Klassifikation wurde im Rahmen des 4. „World Symposium on Pulmonary Hypertension“ in Dana Point im Februar 2008 besprochen, aber noch nicht publiziert.

Lungenhochdruck bei SSc ist eine Komplikation, die isoliert (APAH) oder in Kombination mit einer ILD (PH, Gruppe 3 nach Venedig-Klassifikation) auftreten kann. Der Krankheitsverlauf ist progredient. Die mittels Einschwemmkatheteruntersuchung ermittelte Prävalenz der APAH liegt bei ca. 8\% der SSc-Patienten [105].

\section{Pathogenese}

Die Pathogenese der PAH ist nicht vollständig geklärt. Bisher sind Störungen in drei Achsen identifiziert: Endothelin (ET)-, NO- und Prostazyklin $\left(\mathrm{PGI}_{2}\right.$ )-Signalweg (s. @ Abb. 6). Durch eine Überexpression von ET-1 kommt es zur vermehrten Vasokonstriktion, Zellproliferation und Hypertrophie sowie Erhöhung des Gefäßtonus. Durch die Verminderung von NO und $\mathrm{PGI}_{2}$ kommt es jeweils zur Herabsetzung von Vasodilatation, verminderter Antiproliferation und -inflammation, Hemmung der Thrombozytenfunktion und Gefäßremodeling sowie vermehrten Rechtsherzhypertrophie. Zusammenfassend entsteht also ein Ungleichgewicht zwischen Vasokonstriktoren und -dilatatoren bzw. proliferativ und antiproliferativ wirksamen Substanzen. Die Kenntnisse über die Signalwege - insbesondere auch über die Endothelinrezeptoren [106] - haben die Grundlage für neue zielgerichtete Therapieformen geliefert.

In einer aktuellen Untersuchung wurden die profibrotischen Eigenschaften von ET-1 näher überprüft: es fanden sich Hinweise, dass ET- 1 und TGF- $\beta$ über unterschiedliche Signalwege die Apoptose von Lungenfibroblasten hemmen [107]. Die Kenntnisse über die profibrotischen Eigenschaften von ET-1 haben dazu geführt, dass die Wirksamkeit von Bosentan im Rahmen der BUILD-Studien (Bosentan Use in Interstitial Lung Disease; BUILD-1: bei IPF, BUILD-2: bei SSc-ILD) überprüft wurden: zusammenfassend zeigte sich kein signifikanter Vorteil dieses Behandlungskonzeptes $[108,109]$ : es zeigte sich lediglich ein Trend zur Verzögerung des Krankheitsprogresses bzw. Todeseintritts unter Bosentan. 
Therapie

Die Behandlung einer PAH umfasst supportive (u. a. Langzeitsauerstoff-, Diuretikatherapie) und spezifische medikamentöse Maßnahmen, die gezielt in die Regulation des Gefäßtonus eingreifen. Grundsätzlich wird für APAH-SSc eine Antikoagulation empfohlen [104]. Zur Abschätzung der Indikation für eine spezifische Therapie dienen die vier Funktionsklassen (FC) nach NYHA/WHO, die mit der Überlebenszeit korrelieren [110]. In Deutschland sind für die Behandlung der APAH-CTD die Endothelinrezeptorantagonisten (ERA) Bosentan [111,112], Sitaxsen$\tan$ [113 - 115], Ambrisentan [116] sowie der Phosphodieasterase-5-Hemmer (PDE5i) Sildenafil [117] zugelassen. Bosentan wirkt unselektiv auf Endothelinrezeptoren, Sitaxsentan und Ambrisentan über den Endothelinrezeptor $\mathrm{A}\left(\mathrm{ET}_{\mathrm{A}}\right)$.

Die Studien haben positive Therapieeffekte vor allem hinsichtlich der Belastbarkeit (Verlängerung der Gehstrecke im 6-min-Gehtest) $[111,113,114,116,117]$, Verbesserung der FC $[113,116,117]$, Dauer des progressionsfreien Intervalls [116], der Mortalität [115] sowie der BNP-Konzentration [116] belegt. Nach den Dana-Point-Empfehlungen sollte bereits ab FC II eine spezifische medikamentöse Behandlung mit einem ERA oder Sildenafil erfolgen. In der EU sind bislang nach den Ergebnissen der EARLY-Studie [118] Bosentan sowie Ambrisentan [116] ab dieser FC zugelassen, die anderen Präparate ab FC III. Für schwere Fälle (FC III/ IV) kann grundsätzlich alternativ oder zusätzlich als Prostatazyklin-Analogon inhalatives Iloprost zur Anwendung kommen [119]. Kalziumantagonisten spielen eine untergeordnete Rolle. Bei Therapieversagen sind zunehmend Kombinationstherapien vielversprechend, z.B. mit ERA und PDE5i [120,121]. Vor Einleitung einer Kombinationstherapie wird in vielen Zentren eine erneute Rechtsherzkatheteruntersuchung vorgenommen. Die Rolle von NT-proBNP (N-terminales pro-Brain Natriuretic Peptide) als Verlaufsparameter unter medikamentöser Therapie wird diskutiert [122]. Als letzte Therapieoptionen bleiben Ballonatrioseptostomie und LTx [102].

Die Dringlichkeit einer Therapie der PH bei Patienten mit SSc-ILD wird dadurch verschärft, dass diese Patienten eine schlechtere Prognose aufweisen als diejenigen ohne PH [123,124]. Darüber hinaus haben SSc-Patienten mit PAH eine schlechtere Prognose als Patienten mit idiopathischer PAH [125]. Eine latente PAH (PAH unter Belastung) als Ausdruck einer frühen PAH scheint eine häufige Diagnose bei SSc-Patienten zu sein [126,127], sodass die Prävalenz der PAH bei SSc (manifest und latent) höher liegen dürfte als bisher angenommen.

\section{Zusammenfassung und Ausblick}

$\nabla$

Die Lungenbeteiligung bei systemischer Sklerodermie stellt eine wesentliche Organmanifestation dar. Sie hat eine erhebliche Relevanz für die Prognose der Erkrankung und ist unabhängig vom Ausmaß der Hautmanifestationen [128]. Mittlerweile wird der Bedeutung der Lungenbeteiligung Rechnung getragen, indem frühzeitige und regelmäßige Screening-Untersuchungen im Rahmen eines interdisziplinären Behandlungskonzeptes empfohlen werden. Doch auch bei frühzeitiger Diagnosestellung bleibt die Therapie schwierig: während durch Einführung spezifischer Behandlungsstrategien Erfolge in der PAH-Therapie vorliegen, existiert hinsichtlich der ILD keine sicher wirksame Behandlung. Bessere Kenntnisse über die Pathophysiologie haben zu Untersuchungen geführt, die antifibrotische oder cytokinmodulierende Ansätze in den Mittelpunkt stellen:
Ein rekombinanter humaner anti-TGF- $\beta 1$-Antikörper (CAT-192) wurde im Rahmen einer randomisierten, placebo-kontrollierten Multicenterstudie (Phase 1/2) bei Patienten mit einer Frühform einer dcSSc untersucht [129]. Die Therapie mit Dosierungen bis zu $10 \mathrm{mg} / \mathrm{kg}$ Körpergewicht zeigte allerdings keine Wirksamkeit bei den eingeschlossenen 45 Patienten.

Ziel von gerichteten Therapieversuchen ist ferner Interleukin 13 (IL-13), das die Proliferation von B-Zellen und Antikörperproduktion induziert. Ferner fördert es die Differenzierung von Monozyten und hemmt die Bildung von inflammatorischen Zytokinen, wie z.B. Interleukin-1ß. IL-13 mRNA konnte in Alveolarmakrophagen von Gesunden und Patienten mit Lungenfibrose nachgewiesen werden. Es wurde vermutet, dass die Synthese von Interleukin-13 im Rahmen von entzündlichen Lungenerkrankungen hochreguliert wird [130]. Aktuell wird eine Studie durchgeführt, die placebo-kontrolliert den monoklonalen IL-13-Antikörper QAX576 bei Patienten mit SSc-ILD hinsichtlich der Wirksamkeit (inklusive Lungenfunktionsprüfung) und Verträglichkeit untersucht (http://clinicaltrials.gov). Dieser Antikörper könnte einen besonderen Therapieansatz darstellen, da Polymorphismen (rs638376G bzw. rs5946040G) im IL-13R $\alpha 2$-( $\alpha 2$-Kette des IL-13Rezeptors)Gen mit SSc bzw. dcSSc assoziiert sind [131].

Perspektiven sind also gegeben - eine weitere Erforschung der Pathogenese der Erkrankung ist aber unabdingbar, um aus dem besseren Verständnis der Erkrankung weitere Behandlungsstrategien abzuleiten.

\section{Interessenkonflikte}

Für keinen der Autoren des vorliegenden Artikels besteht ein Interessenkonflikt.

\section{Literatur}

1 Lorenz J. Pneumologie. Stuttgart: Thieme Verlag, 2004: 379-381

2 Gintrac M. Note sur la sclerodermie. Rev Med Chir Paris 1847; 2: 263 281

3 LeRoy EC, Black C, Fleischmajer R et al. Scleroderma (systemic sclerosis): classification, subsets and pathogenesis. J Rheumatol 1988; 15 : $202-205$

4 LeRoy EC, Medsger TA Jr. Criteria for the classification of early systemic sclerosis. J Rheumatol 2001; 28: 1573-1576

5 Johnson SR, Feldman BM, Hawker GA. Classification criteria for systemic sclerosis subsets. J Rheumatol 2007; 34: 1855-1863

6 Black CM. The Aetiopathogenesis Of Systemic Sclerosis: Thick Skin Thin Hypotheses. The Parkes Weber Lecture 1994. JR Coll Physicians London 1995; 29: 119-130

7 Arbeitsgemeinschaft dermatologische Forschung. Klinik der progressiven systemischen Sklerodermie (PSS). Hautarzt 1986; 37: 320 - 324

8 Subcommittee for Scleroderma Criteria of the American Rheumatism Association Diagnostic and Therapeutic Criteria Committee. Preliminary criteria for the classification of systemic sclerosis (scleroderma). Arthritis Rheum 1980; 23: 581-590

9 Benan M, Hande I, Gul O. The natural course of progressive systemic sclerosis patients with interstitial lung involvement. Clin Rheumatol 2007; 26: 349- 354

10 Clements P, Lachenbruch P, Seibold JR et al. Inter- and intraobserver variability of total skin thickness score (modified Rodnan TSS) in systemic sclerosis. J Rheumatol 1995; 22: $1281-1285$

11 Verrecchia F, Laboureau J, Verola $O$ et al. Skin involvement in scleroderma - where histological and clinical scores meet. Rheumatology 2007; 46: $833-841$

12 Rodnan GP, Lipinski E, Luksick J. Skin thickness and collagen content in progressive systemic sclerosis and localized scleroderma. Arthritis Rheum 1979; 22: $130-140$

13 Czirjak L, Nagy Z, Aringer $M$ et al. The EUSTAR model for teaching and implementing the modified Rodnan skin score in systemic sclerosis. Ann Rheum Dis 2007; 66: 966-969 
14 Steen VD, Oddis CV, Conte CG et al. Incidence of systemic sclerosis in allegheny county, Pennsylvania: A twenty-year study of hospital-diagnosed cases, 1963 - 1982. Arthritis \& Rheum 1997; 40: 441 - 445

15 Mayes MD. Scleroderma epidemiology [review]. Rheum Dis Clin North Am 2003; 29: 239-254

16 Vonk MC, Broers B, Heijdra YF et al. Systemic sclerosis and its pulmonary complications in the Netherlands an epidemiological study. Ann Rheum Dis 2009; 68: 961 - 965

17 Mayes MD, Lacey JV Jr, Beebe-Dimmer J et al. Prevalence, incidence, survival, and disease characteristics of systemic sclerosis in a large US population. Arthritis Rheum 2003; 48: 2246-2255

18 Walker UA, Tyndall A, Czirjak L et al. Clinical risk assessment of organ manifestations in systemic sclerosis: a report from the EULAR Scleroderma Trials and Research group database. Ann Rheum Dis 2007; 66: $754-763$

19 Hunzelmann N, Genth E, Krieg T et al. The registry of the German Network for Systemic Scleroderma: frequency of disease subsets and patterns of organ involvement. Rheumatology (Oxford) 2008; 47: 1185 1192

20 Arnett FC, Cho M, Chatterjee S et al. Familial occurrence frequencies and relative risks for systemic sclerosis (scleroderma) in three United States cohorts. Arthritis Rheum 2001; 44: 1359-1362

21 Shahin AA. Pulmonary involvement in systemic sclerosis. Treat Respir Med 2006; 5: $429-436$

22 Pontifex EK, Hill CL, Roberts-Thomsen P. Risk factors for lung cancer in patients with scleroderma: a nested case-control study. Ann Rheum Dis 2007; 66: $551-553$

23 Steen VD, Costantino JP, Shapiro AP et al. Outcome of renal crisis in systemic sclerosis: relation to availability of angiotensin converting enzyme (ACE) inhibitors. Ann Intern Med 1990; 113: 352 - 357

24 Steen VD, Medsger TA. Changes in causes of death in systemic sclerosis, 1972 - 2002. Ann Rheum Dis 2007; 66: 940 - 944

25 Steen VD, Lucas $M$, Fertig $N$ et al. Pulmonary arterial hypertension and severe pulmonary fibrosis in systemic sclerosis patients with a nucleolar antibody. J Rheumatol 2007; 34: 2230-2235

26 Ferri C, Valentini G, Cozzi F et al. Systemic sclerosis study group of the Italian Society of Rheumatology (SIR-GSSSc). Systemic sclerosis: demographic, clinical, and serological features and survival in 1012 Italian patients. Medicine 2002; 81: 139

27 Silver RM, Clements PJ. Interstitial lung disease in systemic sclerosis: optimizing evaluation and management. Scleroderma Care Research 2003; $1: 3-11$

28 D'Angelo WA, Fries JF, Masi AT et al. Pathological observations in systemic sclerosis (scleroderma): a study of fifty-eight autopsy cases and fifty-eight matched controls. Am J Med 1969; 46: 428 - 440

29 Weaver AL, Divertie MB, Titus JL. Pulmonary scleroderma. Dis Chest 1968; 54: 490 - 498

30 McNearney TA, Reveille JD, Fischbach M et al. Pulmonary involvement in systemic sclerosis: associations with genetic, serologic, sociodemographic, and behavioral factors. Arthritis \& Rheumatism 2007; 57: $318-326$

31 Mouthon L, Bérézne A, Brauner $M$ et al. [Interstitial lung disease in systemic sclerosis]. Rev Mal Respir 2007; 24: 1035-1046

32 Hansell DM, Kerr IA. The role of high resolution computed tomography in the diagnosis of interstitial lung disease. Thorax 1991; 46: 77-84

33 Desai SR, Veeraraghavan S, Hansell DM et al. CT features of lung disease in systemic sclerosis: comparison with idiopathic pulmonary fibrosis and non-specific interstitial pneumonia. Radiology 2004; 232: 560 567

34 Camiciottoli G, Orlandi I, Bartolucci $M$ et al. Lung CT densitometry in systemic sclerosis: correlation with lung function, exercise testing, and quality of life. Chest 2007; 131: 672-681

35 Bellia M, Cannizzaro F, Scichilone $N$ et al. HRCT and scleroderma: semiquantitative evaluation of lung damage and functional abnormalities. Radiol Med 2009; 114: 190-203

36 Clements PJ, Goldin JG, Kleerup EC et al. Regional differences in bronchoalveolar lavage and thoracic high-resolution computed tomography results in dyspneic patients with systemic sclerosis. Arthritis \& Rheum 2004; 50: 1909 - 1917

37 Steen VD, Conte C, Owens GR et al. Severe restrictive lung disease in systemic sclerosis. Arthritis \& Rheum 1994; 37: 1283-1289

38 Marcisz CE, Kucharz J, Brzezinska-Wcislo L et al. Pulmonary functional abnormalities in asymptomatic patients with systemic sclerosis. Eur J Intern Med 2003; 14: 162-165
39 Buch $M H$, Denton CP, Furst DE et al. Submaximal exercise testing in the assessment of interstitial lung disease secondary to systemic sclerosis: reproducibility and correlations of the 6-min walk test. Ann Rheum Dis 2007; 66: 169-173

40 Garin MC, Highland $K B$, Silver RM et al. Limitations of the 6-minute walk test in interstitial lung disease and pulmonary hypertension in scleroderma. J Rheumatol 2009; 36: 330 - 336

41 Ooi GC, Mok MY, Tsang KW et al. Interstitial lung disease in systemic sclerosis. An HRCT-clinical correlative study. Acta Radiologica 2003; 44: $258-264$

42 Goh NS, Desai SR, Veeraraghavan S et al. Interstitial lung disease in systemic sclerosis: a simple staging system. Am J Respir Crit Care Med 2008; 177: 1248 - 1254

43 Ravini M, Ferraro G, Barbieri B et al. Changing strategies of lung biopsies in diffuse lung diseases: the impact of video-assisted thoracoscopy. Eur Respir J 1998; 11: 99 - 103

44 Badesch DB, Abman SH, Simmoneau G et al. Medical therapy for pulmonary arterial hypertension: updated ACCP evidence-based clinical practice guidelines. Chest 2007; 131: 1917-1928

45 Hachulla E, Carpentier P, Gressin Vet al. Risk factors for death and the 3 year survival of patients with systemic sclerosis: the French ItinérAIRSclérodermie study. Rheumatology (Oxford) 2009; 48: 304-208

46 American Thoracic Society/European Respiratory Society. American Thoracic Society/European Respiratory Society International Multidisciplinary Consensus Classification of the Idiopathic Interstitial Pneumonias. Am J Resp Crit Care Med 2002; 165: 277 - 304

47 Bradley B, Branley HM, Egan JJ et al. Interstitial lung disease guideline: the British Thoracic Society in collaboration with the Thoracic Society of Australia and New Zealand and the Irish Thoracic Society. Thorax 2008; 63 (Suppl. 5): v1 - 58

48 Katzenstein AL, Fiorelli RF. Nonspecific interstitial pneumonia/fibrosis. Histologic features and clinical significance. Am J Surg Pathol 1995; 18 $136-147$

49 Kim DS, Yoo B, Lee JS et al. The major histopathologic pattern of pulmonary fibrosis in scleroderma is nonspecific interstitial pneumonia. Sarcoidosis Vasc Diffuse Lung Dis 2002; 19: 121-127

50 Bouros D, Wells AU, Nicholson AG et al. Histopathologic subsets of fibrosing alveolitis in patients with systemic sclerosis and their relationship to outcome. Am J Respir Crit Care Med 2002; 165: 1581 - 1586

51 deCarvalho EF, Parra ER, deSouza $R$ et al. Arterial and interstitial remodelling processes in non-specific interstitial pneumonia: systemic sclerosis versus idiopathic. Histopathology 2008; 53: 193 - 204

52 Marie I, Dominique S, Levesque $H$ et al. Esophageal involvement and pulmonary manifestations in systemic sclerosis. Arthritis Rheum 2001; 45: $346-354$

53 Marie I, Ducrotte P, Denis P et al. Oesophageal mucosal involvement in patients with systemic sclerosis receiving proton pump inhibitor therapy. Aliment Pharmacol Ther 2006; 24: 1593-1601

54 Savarino E, Bazzica M, Zentilin P et al. Gastroesophageal reflux and pulmonary fibrosis in scleroderma: a study using $\mathrm{pH}$-impedance monitoring. Am J Respir Crit Care Med 2009; 179: 408 -413

55 Jain R, Shaul PW, Borok Z et al. Endothelin-1 induces alveolar epithelialmesenchymal transition through endothelin type A receptor mediated production of TGF-beta 1. Am J Respir Cell Mol Biol 2007; 37: 38 - 47

56 Hagimoto N, Kuwano K, Nomoto $Y$ et al. Apoptosis and expression of Fas/Fas ligand mRNA in bleomycin-induced pulmonary fibrosis in mice. Am J Respir Cell Mol Biol 1997; 16: 91 - 101

57 Hoyles RK, Khan K, Shiwen X et al. Fibroblast-specific perturbation of transforming growth factor beta signaling provides insight into potential pathogenic mechanisms of scleroderma-associated lung fibrosis: exaggerated response to alveolar epithelial injury in a novel mouse model. Arthritis Rheum 2008; 58: 1175 - 1188

58 Sonnylal S, Denton CP, Zheng B et al. Postnatal induction of transforming growth factor beta signaling in fibroblasts of mice recapitulates clinical, histologic, and biochemical features of scleroderma. Arthritis Rheum 2007; 56: 334-344

59 Corrin B, Butcher D, McAnulty BJ et al. Immunohistochemical localization of TGF- $\beta 1$ in the lungs of patients with systemic sclerosis, cryptogenic fibrosing alveolitis and other lung disorders. Histopathology 1994; 24: $145-150$

60 Branley HM, du Bois RM, Wells AU et al. PET scanning of macrophages in patients with scleroderma fibrosing alveolitis. Nucl Med Biol 2008; 35 : $901-909$ 
61 Gourh P, Tan FK, Assassi S et al. Association of the PTPN22 R620W polymorphism with anti-topoisomerase I- and anticentromere antibodypositive systemic sclerosis. Arthritis Rheum 2006; 54: 3945 - 3953

62 Mattuzzi S, Barbi S, Carletto A et al. Association of polymorphisms in the IL1B and IL2 genes with susceptibility and severity of systemic sclerosis. J Rheumatol 2007; 34: 997-1004

63 Fonseca C, Lindahl GE, Ponticos $M$ et al. A polymorphism in the CTGF promotor region associated with systemic sclerosis. N Engl J Med 2007; 357: 1210 - 1220

64 Ates $O$, Müsellim B, Ongen $G$ et al. NRAMP1 (SLC11A1): A plausible candidate gene for systemic sclerosis (SSc) with interstitial lung involvement. J Clin Immunol 2008; 28: $73-77$

65 Sumita Y, Sugiura T, Kawaguchi Y et al. Genetic polymorphisms in the surfactant proteins in systemic sclerosis in Japanese: $\mathrm{T} / \mathrm{T}$ genotype at $1580 \mathrm{C} / \mathrm{T}$ (Thr131Ile) in the SP-B gene reduces the risk of interstitial lung disease. Rheumatology (Oxford) 2008; 47: 289-291

66 Dieudé P, Guedj W, Wipff $J$ et al. Association between the IRF5 rs2004640 functional polymorphism and systemic sclerosis: a new perspective for pulmonary fibrosis. Arthritis Rheum 2009; 60: 225 233

67 Renzoni E, Lympany P, Sestini P et al. Distribution of novel polymorphisms of the interleukin- 8 and cxc receptor 1 und 2 genes in systemic sclerosis and cryptogenic fibrosing alveolitis. Arthritis \& Rheumatism 2000; 43: $1633-1640$

68 Ates $O$, Müsellim B, Ongen $G$ et al. Association between interleukin 10 gene (IL10) polymorphisms and systemic sclerosis with interstitial lung involvement. Rheumatol Int 2008; 28: 1123 -1126

69 Bredemeier M, Chies JA, Wieck A et al. TCRBV20S1 and TCRBV3S1 Gene Segment Polymorphisms in Systemic Sclerosis. J Rheumatol 2008; 35: $1058-1063$

70 Goh NS, Veeraraghavan S, Desai SR et al. Bronchoalveolar lavage cellular profiles in patients with systemic sclerosis-associated interstitial lung disease are not predictive of disease progression. Arthritis Rheum 2007; 56: 2005-2012

71 Martinez JA, Nishimura C, Guatura SB et al. Elevation of soluble interleukin-2 receptor levels in the bronchoalveolar lavage from patients with systemic sclerosis. Rheumatol Int 2001; 21: $122-126$

72 Andersen GN, Nilsson K, Pourazar J et al. Bronchoalveolar matrix metalloproteinase 9 relates to restrictive lung function impairment in systemic sclerosis. Respir Med 2007; 101: 2199-2206

73 Scheja A, Larsen $K$, Todorova L et al. BALF-derived fibroblasts differ from biopsy-derived fibroblasts in systemic sclerosis. Eur Respir J 2007; 29 : $446-452$

74 Strange C, Bolster MB, Roth MD et al. Bronchoalveolar lavage and response to cyclophosphamide in scleroderma interstitial lung disease. Am J Respir Crit Care Med 2008; 177: 91 - 98

75 Steen VD. The many faces of scleroderma. Rheum Dis Clin North Am 2008; 34: 1-15; v.

76 Kuwana M, Medsger TA Jr, Wright TM. T cell proliferative response induced by DNA topoisomerase I in patients with systemic sclerosis and healthy donors. J Clin Invest 1995; 96: 586-596

77 Ioannidis JP, Vlachoyiannopoulos PG, Haidich AB et al. Mortality in systemic sclerosis: an international meta-analysis of individual patient data. Am J Med 2005; 118: 2-10

$78 \mathrm{Hu} P Q$ Hurwitz AA, Oppenheim JJ. Immunization with DNA topoisomerase I induces autoimmune responses but not scleroderma-like pathologies in mice. J Rheumatol 2007; 34: 2243-2252

79 Takahashi H, Kuroki Y, Tanaka $H$ et al. Serum levels of surfactant proteins $\mathrm{A}$ and $\mathrm{D}$ are useful biomarkers for interstitial lung disease in patients with systemic sclerosis. Am J Respir Crit Care Med 2000; 162: $258-263$

80 Yanaba K, Hasegawa M, Hamaguchi Y et al. Longitudinal analysis of serum KL-6 levels in patients with systemic sclerosis: association with the activity of pulmonary fibrosis. Clin Exp Rheumatol 2003; 21: 429-436

81 Kumánovics G, Minier T, Radics J et al. Comprehensive investigation of novel serum markers of pulmonary fibrosis associated with systemic sclerosis and dermato/polymyositis. Clin Exp Rheumatol 2008; 26: $414-420$

82 Hara T, Ogawa F, Yanaba K et al. Elevated serum concentrations of polymorphonuclear neutrophilic leukocyte elastase in systemic sclerosis: association with pulmonary fibrosis. J Rheumatol 2009; 36: 99-105

83 Nomura S, Inami N, Ozaki Y et al. Significance of microparticles in progressive systemic sclerosis with interstitial pneumonia. Platelets 2008; 19: $192-198$
84 Malerba M, Radaeli A, Ragnoli B et al. Exhaled nitric oxide levels in systemic sclerosis with and without pulmonary involvement. Chest 2007; 132: $575-580$

85 Tiev KP, Cabane J, Aubourg F et al. Severity of scleroderma lung disease is related to alveolar concentration of nitric oxide. Eur Respir J 2007; 30: $26-30$

86 Tashkin DP, Elashoff R, Clements PJ et al. Cyclophosphamide versus placebo in scleroderma lung disease. N Engl J Med 2006; 354: 2655-2666

87 Tashkin DP, Elashoff R, Clements PJ et al. Effects of 1-year treatment with cyclophosphamid on outcomes at 2 years in scleroderma lung disease. Am J Respir Crit Care Med 2007; 176: 1026-1034

88 Tzelepis GE, Plastiras SC, Karadimitrakis SP et al. Determinants of pulmonary function improvement in patients with scleroderma and interstitial lung disease. Clin Exp Rheumatol 2007; 25: 734-739

89 Hoyles RK, Ross WE, Wellsbury J et al. A multicenter, prospective, randomized, double-blind, placebo-controlled trial of corticosteroids and intravenous Cyclophosphamide followed by oral Azathioprine for the treatment of pulmonary fibrosis in scleroderma. Arthritis \& Rheumatism 2006; 54: 3962 - 3970

90 Bérézne A, Ranque B, Valeyre $D$ et al. Therapeutic strategy combining intravenous cyclophosphamide followed by oral azathioprine to treat worsening interstitial lung disease associated with systemic sclerosis: a retrospective multicenter open-label study. J Rheumatol 2008; 35: $1064-1072$

91 Dheda K, Lalloo UG, Casim B et al. Experience with azathioprine in systemic sclerosis associated with interstitial lung disease. Clin Rheumatol 2004; 23: 306-309

92 Sabnani I, Zucker MJ, Rosenstein ED et al. A novel therapeutic approach to the treatment of scleroderma-associated pulmonary complications: safety and efficacy of combination therapy with imatinib and cyclophosphamid. Rheumatology (Oxford) 2009; 48: 49-52

93 Paniagua RT, Sharpe O, Ho PP et al. Selective tyrosine kinase inhibition by imatinib mesylate for the treatment of autoimmune arthritis. J Clin Invest 2006; 116: $2633-2642$

94 Baroni SS, Santillo M, Bevilacqua $F$ et al. Stimulatory autoantibodies to the PDGF receptor in systemic sclerosis. N Engl J Med 2006; 354: $2667-2676$

95 Kallenberg CG, Jansen HM, Elema JD et al. Steroid-responsive interstitial pulmonary disease in systemic sclerosis. Monitoring by bronchoalveolar lavage. Chest 1984; 86: 489-492

96 Krishna Sumanth M, Sharma VK, Khaitan BK et al. Evaluation of oral methotrexate in the treatment of systemic sclerosis. International Journal of Dermatology 2007; 46: 218-223

97 Imokawa S, Colby T, Leslie KO et al. Methotrexate pneumonitis: review of the literature and histopathological findings in nine patients. Eur Respir J 2000; 15: 373-381

$98 \mathrm{Au}$ K, Khanna D, Clements PJ et al. Current concepts in disease-modifying therapy for systemic sclerosis-associated interstitial lung disease: lessons from clinical trials. Curr Rheumatol Rep 2009; 11: 111 - 119

99 Nash RA, McSweeney PA, Crofford LJ et al. High-dose immunosuppressive therapy (HDIT) and autologous hematopoietic cell transplantation for severe systemic sclerosis: long-term follow-up of the US multicenter pilot study. Blood 2007; 110: 1388-1396

100 Shiratsuchi M, Motomura S, Abe $Y$ et al. Long-term follow-up after nonmyeloablative allogeneic hematopoietic stem cell transplantation for systemic sclerosis. Clin Rheumatol 2008; 27: 1207-1209

101 Williams TJ, Wilson JW. Challenges in pulmonary fibrosis: 7-novel therapies and lung transplantation. Thorax 2008; 63: 277-284

102 Schachna L, Medsger TA Jr, Dauber JH et al. Lung transplantation in scleroderma compared with idiopathic pulmonary fibrosis and idiopathic pulmonary arterial hypertension. Arthritis Rheum 2006; 54: 3954-3961

103 Galiè N, Torbicki A, Barst $R$ et al. Guidelines on diagnosis and treatment of pulmonary arterial hypertension. The Task Force on Diagnosis and Treatment of Pulmonary Arterial Hypertension of the European Society of Cardiology. Eur Heart J 2004; 25: 2243-2278

104 Olschewski H, Hoeper MM, Borst MM et al. [Diagnosis and therapy of chronic pulmonary hypertension]. Pneumologie 2006; 60: 749-771

105 Hachulla E, Gressin V, Guillevin et al. Early detection of pulmonary arterial hypertension in systemic sclerosis: a French nationwide prospective multicenter study. Arthritis Rheum 2005; 52: 3792 - 3800

106 Murakoshi N, Miyauchi T, Kakinuma Y et al. Vascular endothelin-B receptor system in vivo plays a favourable inhibitory role in vascular remodeling after injury revealed by endothelin-B receptor-knockout mice. Circulation 2002; 106: 1991 - 1998 
107 Kulasekaren P, Scavone CA, Rogers DS et al. Endothelin-1 and TGF-\{beta\} independently induce fibroblast resistance to apoptosis via AKT activation. Am J Respir Cell Mol Biol 2009; (im Druck)

108 King TE Jr, Behr J, Brown KK et al. BUILD-1: a randomized placebo-controlled trial of bosentan in idiopathic pulmonary fibrosis. Am J Respir Crit Care Med 2008; 177: 75-81

109 Seibold JR, Black CM, Denton CP et al. Bosentan versus placebo in interstitial lung disease secondary to systemic sclerosis (SSc): the BUILD-2 Study [abstract]. Proc Am Thorac Soc 2006; 3: A243

110 D'Alonzo GE, Barst RJ, Ayres SM et al. Survival in patients with primary pulmonary hypertension. Results form a national prospective registry. Ann Intern Med 1991; 115: 343 - 349

111 Rubin LJ, Badesch DB, Barst RJ et al. Bosentan therapy for pulmonary arterial hypertension. N Engl J Med 2002; 346: 896-903

112 McLaughlin $V V$. Survival in patients with pulmonary hypertension treated with first-line bosentan. Eur J Clin Invest 2006; 36 (Suppl. 3): $10-15$

113 Barst RJ, Langleben D, Badesch D et al. Treatment of pulmonary arterial hypertension with the selective endothelin-A receptor antagonist sitaxsentan. J Am Coll Cardiol 2006; 47: 2049-2056

114 Girgis RE, Frost AE, Hill NS et al. Selective endothelinA receptor antagonism with sitaxsentan for pulmonary arterial hypertension associated with connective tissue disease. Ann Rheum Dis 2007; 66: $1467-1472$

115 Benza RL, Barst RJ, Galié $N$ et al. Sitaxsentan for the treatment of pulmonary arterial hypertension: a 1-year, prospective, open-label observation of outcome and survival. Chest 2008; 134: 775-782

116 Galiè N, Olschewski H, Oudiz RJ et al. Ambrisentan for the treatment of pulmonary arterial hypertension: results of the ambrisentan in pulmonary arterial hypertension, randomized, double-blind, placebocontrolled, multicenter, efficacy (ARIES) study 1 and 2. Circulation 2008; 117: 3010-3019

117 Badesch DB, Hill NS, Burgess $G$ et al. Sildenafil for pulmonary arterial hypertension associated with connective tissue disease. J Rheumatol 2007; 34: 2417-2422

118 Galiè N, Rubin LJ, Hoeper MM et al. Treatment of patients with mildly symptomatic pulmonary arterial hypertension with bosentan (EARLY study): a double-blind, randomised controlled trial. Lancet 2008; 371: $2093-2100$

119 Olschewski H, Simonneau G, Galie N et al. Inhaled iloprost for severe pulmonary hypertension. N Engl J Med 2002; 347: 322 - 329
120 Hoeper MM, Markevych I, Spiekerkoetter E et al. Goal-oriented treatment and combination therapy for pulmonary arterial hypertension. Eur Respir J 2005; 26: 858 - 863

121 Porhownik NR, Al-Sharif H, Bshouty Z. Addition of sildenafil in patients with pulmonary arterial hypertension with inadequate response to bosentan monotherapy. Can Respir J 2008; 15: 427-430

122 Dimitroulas T, Giannakoulas G, Karvounis H et al. N-terminal probrain natriuretic peptide as a biochemical marker in the evaluation of bosentan treatment in systemic-sclerosis-related pulmonary arterial hypertension. Clin Rheumatol 2008; 27: 655-658

123 Trad S, Amoura Z, Beigelman C et al. Pulmonary arterial hypertension is a major mortality factor in diffuse systemic sclerosis, independent of interstitial lung disease. Arthritis Rheum 2006; 54: 184-191

124 Mathai SC, Hummers LK, Champion HC et al. Survival in pulmonary hypertension associated with the scleroderma spectrum of diseases: impact of interstitial lung disease. Arthritis Rheum 2009; 60: 569577

125 Girgis RE, Mathai SC, Krishnan JA et al. Long-term outcome of bosentan treatment in idiopathic pulmonary arterial hypertension and pulmonary arterial hypertension associated with the scleroderma spectrum of diseases. J Heart Lung Transplant 2005; 24: 1626-1631

126 Huez S, Roufosse F, Vachiéry J-L et al. Isolated right ventricular dysfunction in systemic sclerosis: latent pulmonary hypertension? Eur Respir J 2007; 30: 928 - 936

127 Steen VD, Chou M, Shanmugam V et al. Exercise-induced pulmonary arterial hypertension in patients with systemic sclerosis. Chest 2008 ; 134: $146-151$

128 Hanitsch LG, Burmester G-R, Witt C et al. Skin sclerosis is only of limited value to identify SSc patients with severe manifestations - an analysis of a distinct patient subgroup of the German Systemic Sclerosis Network (DNSS) Register. Rheumatology (Oxford) 2009; 48: 70 73

129 Denton CP, Merkel PA, Furst DE et al. Recombinant human anti-transforming growth factor beta1 antibody in systemic sclerosis: a multicenter, randomized, placebo-controlled phase I/II trial of CAT-192. Arthritis Rheum 2007; 56: $323-333$

130 Hancock A, Armstrong L, Gama R et al. Production of interleukin 13 by alveolar macrophages from normal and fibrotic lung. Am J Respir Cell Mol Biol 1998; 18: 60-65

131 Granel B, Allanore $Y$, Chevillard C et al. IL13RA2 gene polymorphisms are associated with systemic sclerosis. J Rheumatol 2006; 33: 2015 2019 